\title{
Bacteremia as a risk factor for variceal upper gastrointestinal tract bleeding in cirrhotic patients: a hospital-based study
}

Mohamad Husseini Saeid Zidan', Sahar Gouda Zaghloul', Waseem Mohamed Seleem, Hanan Samir Ahmed² and Ahmed Ibrahim Gad ${ }^{1 *}$ (D)

\begin{abstract}
Background: The presence of bacteremia as a complication of variceal bleeding in patients with liver cirrhosis had been investigated by many studies. The aim of this study was to assess the bacteremia as a risk factor for variceal upper gastrointestinal tract bleeding in cirrhotic patients. A cross-sectional study was conducted on 99 patients with chronic liver disease divided into three groups: group I included 35 patients presented with first attack of variceal bleeding, group II included 35 patients presented with recurrent attacks of variceal bleeding, and group III included 29 patients with no history of previous variceal bleeding as a control group. Routine laboratory tests were done, upper Gl endoscopy, blood culture, and measurement of procalcitonin level in blood.
\end{abstract}

Results: Patients with recurrent variceal bleeding had statistically $(p<0.05)$ the highest percentage of positive blood culture followed by patients with first variceal bleeding and the control (60\% vs $45.7 \%$ vs $24.1 \%$ ) respectively. In addition to procalcitonin results, patients with recurrent variceal bleeding had statistically the highest values of PCT followed by patients with first variceal bleeding and the control (1.92 vs $0.325 \mathrm{vs} 0.22 \mathrm{ng} / \mathrm{ml}$ ) respectively. Multivariate regression analysis showed that procalcitonin and hemoglobin only was the significant predictors for variceal bleeding. Hemoglobin at cutoff value of $\leq 9.6$ and procalcitonin $(\mathrm{ng} / \mathrm{dl})$ at cutoff value of $>1.76$ is the most specific in predicting bleeding $86.21 \%, 86.21 \%(\mathrm{Cl} 95 \%)$ respectively.

Conclusion: Bacteremia and procalcitonin are risk factor for variceal bleeding in cirrhotic patients. Procalcitonin can be used as easily measurable and surrogate biomarker for bacteremia and variceal bleeding.

Keywords: Cirrhosis, PCT, Bacteremia, Variceal bleeding

\section{Background}

Liver cirrhosis is a chronic disease characterized by the presence of fibrosis and regeneration of nodules in the liver, whose consequences are the development of portal hypertension and liver failure. Liver cirrhosis is a public health and a worldwide problem. It affects all ethnic groups, ages, sex, and it is the cause of high rates of medical consultations, hospital admissions, health expenses, and morbidity and mortality [1]. Portal hypertension is one

\footnotetext{
* Correspondence: ahmedgadmed@yahoo.com

'Internal Medicine Department, Faculty of Medicine, Zagazig University,

Zagazig, Sharkia 44519, Egypt

Full list of author information is available at the end of the article
}

of the complications of liver cirrhosis and characterized by an increased portal pressure gradient leading to other consequences such as splenomegaly, growth of an extensive network of portal-systemic collaterals that shunt portal blood flow to the systemic circulation bypassing the liver, and development of a hyperkinetic circulatory state [2]. Upper gastrointestinal bleeding is a common medical emergency worldwide and refers to bleeding from the esophagus, stomach, or duodenum. Patients present with hematemesis or melena, although hematochezia can occur in the context of a major bleeding and it is typically associated with hemodynamic instability [3]. Variceal bleeding is the second most common cause of UGIB. Approximately, 
half the patients with cirrhosis have gastroesophageal varices as a consequence of portal hypertension. The severity of the underlying cirrhosis is directly related to the probability that the patient will have varices and signs of portal hypertension [4].

Bacterial infections in cirrhotic patients with UGIB are very common. Sepsis is the leading cause of hospitalization and death in intensive care units. Infections directly cause $30-50 \%$ deaths in patients with cirrhosis. The common bacterial infections in patients with cirrhosis include SBP, UTI, pneumonia, bacteremia, and soft-tissue infections [5].
Bacteremia is the presence of bacteria in the blood. The blood is normally a sterile environment, so the detection of bacteria in the blood is always abnormal [6]. Procalcitonin is an ideal marker for bacterial infection should allow an early diagnosis. Inform about the course and prognosis of the disease and facilitate therapeutic intervention. In comparison to other commonly used markers such as C-reactive protein, PCT has a superior diagnostic accuracy in distinguishing bacterial infection from non-infective causes of inflammation and from viral infections [7].

Table 1 Demographic and baseline characteristics of the study groups $(n=99)$

\begin{tabular}{|c|c|c|c|c|c|c|c|c|}
\hline & \multirow{2}{*}{\multicolumn{2}{|c|}{$\begin{array}{l}\text { Group (I) } \\
\text { Patient with first attack } \\
\text { of bleeding }(n=35)\end{array}$}} & \multirow{2}{*}{\multicolumn{2}{|c|}{$\begin{array}{l}\text { Group (II) } \\
\text { Patient with recurrent } \\
\text { bleeding }(n=35)\end{array}$}} & \multirow{2}{*}{\multicolumn{2}{|c|}{$\begin{array}{l}\text { Group (III) } \\
\text { Control patients } \\
(n=29)\end{array}$}} & \multirow[t]{3}{*}{ Test } & \multirow[t]{3}{*}{$p$} \\
\hline & & & & & & & & \\
\hline & No. & $\%$ & No. & $\%$ & No. & $\%$ & & \\
\hline \multicolumn{9}{|l|}{ Age (years) } \\
\hline Mean $\pm S D$ & \multicolumn{2}{|c|}{$54 \pm 9.6$} & \multicolumn{2}{|c|}{$53.7 \pm 10.11$} & \multicolumn{2}{|c|}{$53.7 \pm 9$} & $F, 0.008$ & 0.99 \\
\hline \multicolumn{9}{|l|}{ Sex } \\
\hline Male & 23 & $65.7 \%$ & 19 & $54.3 \%$ & 17 & $58.6 \%$ & \multirow[t]{2}{*}{$x^{2}, 0.965$} & \multirow[t]{2}{*}{0.78} \\
\hline Female & 12 & $34.3 \%$ & 16 & $45.7 \%$ & 12 & $41.4 \%$ & & \\
\hline \multicolumn{9}{|l|}{ HE } \\
\hline No & 29 & $82.9 \%$ & 25 & $71.4 \%$ & 25 & $86.2 \%$ & \multirow[t]{3}{*}{$x^{2}, 5.25$} & \multirow[t]{3}{*}{0.26} \\
\hline Grade I & 3 & $8.6 \%$ & 2 & $5.7 \%$ & 0 & $0 \%$ & & \\
\hline Grade II & 3 & 8.6 & 8 & $22.9 \%$ & 4 & $13.8 \%$ & & \\
\hline \multicolumn{9}{|l|}{ Ascites } \\
\hline No & 10 & $28.6 \%$ & 4 & $11.4 \%$ & 14 & $48.3 \%$ & \multirow[t]{4}{*}{$x^{2}, 17.13$} & \multirow[t]{4}{*}{0.0088} \\
\hline Minimal & 4 & $11.4 \%$ & 3 & $8.6 \%$ & 0 & $0 \%$ & & \\
\hline Moderate & 9 & $25.7 \%$ & 15 & $42.9 \%$ & 12 & $41.4 \%$ & & \\
\hline Severe & 12 & 34.35 & 13 & $37.1 \%$ & 3 & $10.3 \%$ & & \\
\hline \multicolumn{9}{|l|}{ Virology } \\
\hline Negative & 3 & $8.6 \%$ & 3 & $8.6 \%$ & 4 & $13.8 \%$ & \multirow[t]{3}{*}{$x^{2}, 3.85$} & \multirow[t]{3}{*}{0.42} \\
\hline$H B V$ & 2 & $5.7 \%$ & 7 & $20 \%$ & 4 & $13.8 \%$ & & \\
\hline \multirow[t]{2}{*}{$\mathrm{HCV}$} & 30 & $85.7 \%$ & 25 & $71.4 \%$ & 21 & $72.4 \%$ & & \\
\hline & \multicolumn{2}{|c|}{$\begin{array}{l}\text { Group (I) } \\
\text { Patient with first attack } \\
\text { of bleeding }(n=35)\end{array}$} & \multicolumn{2}{|c|}{$\begin{array}{l}\text { Group (II) } \\
\text { Patient with recurrent } \\
\text { bleeding }(n=35)\end{array}$} & \multicolumn{2}{|c|}{$\begin{array}{l}\text { Group (III) } \\
\text { Control patients } \\
(n=29)\end{array}$} & Test & $p$ \\
\hline WBC $\left(\times 10^{3} / \mathrm{mm}^{3}\right)$, median (range) & \multicolumn{2}{|c|}{$9.8(3.3-12.8)$} & 9.0( & & $9.6(4$ & & KW, 0.607 & 0.715 \\
\hline Hemoglobin $(\mathbf{g} / \mathrm{dl})$, mean $\pm S D$ & 8.54 & & 8.35 & & 10.56 & & $\boldsymbol{F}, 17.7$ & $<0.001$ \\
\hline Platelet $\left(\times 10^{3} / \mathrm{mm}^{3}\right)$, mean $\pm S D$ & 110.1 & & 86.17 & & 115.2 & & $\boldsymbol{F}, 7.4$ & 0.001 \\
\hline INR, median (range) & 1.39 & & 1.65 & & 1.22 & $-2.17)$ & KW, 17.8 & $<0.0001$ \\
\hline Creatinine (mg/dl), median (range) & 0.99 & & 0.98 & & 0.77 & $-4.3)$ & KW, 2.79 & 0.247 \\
\hline Urea (mg/dl), median (range) & $24(1$ & & $27(1$ & & $25(1$ & & KW, 0.64 & 0.64 \\
\hline Albumin $(\mathbf{g} / \mathbf{d L})$, mean $\pm S D$ & $2.8 \pm$ & & 2.66 & & 2.98 & & $\mathbf{F}, 2.91$ & 0.05 \\
\hline Total bilirubin (mg/dl), median (range) & 1.26 & & 1.44 & & 1.19 & $-30.9)$ & KW, 1.22 & 0.5 \\
\hline Direct bilirubin (mg/dl), median (range) & 0.77 & & 0.78 & .57) & 0.84 & $-20.8)$ & KW, 0.17 & 0.9 \\
\hline Spleen diameter $(\mathbf{c m})$, median (range) & $12(9$ & & 13.5 & & 10.5 & & KW, 9.86 & $<0.001$ \\
\hline PV diameter $(\mathbf{m m})$, mean $\pm S D$ & 13.76 & & 13.78 & & 13.74 & & $\boldsymbol{F}, 0.066$ & 0.93 \\
\hline
\end{tabular}


PCT increase is observed within 2-3 h. Levels then rise rapidly, reaching a plateau after $6-12 \mathrm{~h}$. PCT concentrations remain high for $48 \mathrm{~h}$, falling to their baseline value within the following 2 days. The half-life is about 20 to $24 \mathrm{~h}$ [8].

Previous clinical studies investigated the association of bacteremia and liver cirrhosis and its complications such as GI bleeding [9-13]. The aim of this study was to assess the bacteremia as a risk factor for variceal upper gastrointestinal tract bleeding in cirrhotic patients.

\section{Methods}

\section{Study design}

A hospital-based cross-sectional study was carried out in the gastroenterology and hepatology unit of Internal Medicine Department at the Faculty of Medicine, Zagazig University Hospitals. The Zagazig University institutional review board approved the study (ZU-IRB\#5470-7-72019). Our study included 99 patients with chronic liver disease divided into three groups: the first group included 35 patients presented with the first attack of variceal bleeding, the second group included 35 patients presented with recurrent attacks of variceal bleeding and the third group included 29 patients with no history of previous variceal bleeding as a diseased control group. Written informed consent was obtained from all individual participants included in the study.

\section{Patients selection and data collection}

To be eligible for this study, the patient had to fulfill the following inclusion criteria: (1) patient aged 18 to 60 years old, (2) patient of both sexes with chronic liver disease with endoscopic evidence of upper GIT varices.

We excluded patient who had causes of bacterial infections (e.g., spontaneous bacterial peritonitis, chest infections, and urinary tract infections), patients who had received antibiotics within 1 week before admission, patients who had non-variceal causes of GIT bleeding including peptic ulcer disease, Mallory-Weiss tear, erosive gastritis or gastric cancer, and patients who had non-bacterial causes that may elevate PCT (false positive) including diseases (ESRD and vasculitis), drugs (IL-2, granulocyte transfusion), and stress as severe trauma and surgery. Eligible patients were subjected to history taking, full physical examination, and investigations to fulfill inclusion and exclusion criteria.

\section{Laboratory determinations and clinical assessments}

The following data were collected for each patient eligible for the study: age, gender, body mass index (BMI), residency, smoking status, hemoglobin A1C (HbA1C), fasting blood glucose (FBG), complete blood count $(\mathrm{CBC})$, international normalized ratio (INR), total bilirubin, direct bilirubin, aspartate transferase (AST), alanine transferase (ALT), albumin, total plasma protein, alkaline phosphatase, creatinine, blood urea nitrogen (BUN), ESR, CRP, urine analysis, and ascitic fluid sample analysis (chemical, cellular and bacteriological). In addition, blood culture and serum procalcitonin measurement were done.

Abdominal ultrasonography (US) with Doppler for assessment of liver status, portal flow, portal vein and bipolar splenic size diameters, and upper GIT endoscopy (PENTAX EC-3890LK ${ }^{\circ}$ ) were performed by an experienced physician who was blinded to the clinical data of the patients.

\section{Assessment procedures}

Serum procalcitonin was measured by Cobas Integra e411 (Roche, Germany) at the clinical pathology department, Zagazig University Hospitals. The assay range:

Table 2 Comparison between studied groups regarding bacteremia and procalcitonin results $(n=99)$

\begin{tabular}{|c|c|c|c|c|c|c|c|c|}
\hline & \multicolumn{2}{|c|}{ Group (I) } & \multicolumn{2}{|c|}{ Group (II) } & \multicolumn{2}{|c|}{ Group (III) } & \multirow[t]{3}{*}{ Test } & \multirow[t]{3}{*}{$P$} \\
\hline & \multicolumn{2}{|c|}{$\begin{array}{l}\text { Patient with first attack } \\
\text { of bleeding }(n=35)\end{array}$} & \multicolumn{2}{|c|}{$\begin{array}{l}\text { Patient with recurrent } \\
\text { bleeding }(n=35)\end{array}$} & \multicolumn{2}{|c|}{$\begin{array}{l}\text { Control patients } \\
(n=29)\end{array}$} & & \\
\hline & No. & $\%$ & No. & $\%$ & No. & $\%$ & & \\
\hline \multicolumn{9}{|l|}{ Blood culture } \\
\hline Positive & 16 & $45.7 \%$ & 21 & $60 \%$ & 7 & $24.1 \%$ & \multirow[t]{5}{*}{$x^{2}, 8.53$} & \multirow[t]{5}{*}{0.001} \\
\hline E.coli & 10 & $28.6 \%$ & 14 & $40 \%$ & 4 & $13.8 \%$ & & \\
\hline Staph. & 4 & $11.4 \%$ & 5 & $14.3 \%$ & 2 & $6.9 \%$ & & \\
\hline Klebseilla & 2 & $5.7 \%$ & 2 & $5.7 \%$ & 1 & $3.4 \%$ & & \\
\hline Negative & 19 & $54.3 \%$ & 14 & $40 \%$ & 22 & $75.9 \%$ & & \\
\hline \multicolumn{9}{|l|}{ Procalcitonin (ng/ml) } \\
\hline Positive & 15 & $42.9 \%$ & 21 & $60 \%$ & 6 & $20.7 \%$ & \multirow[t]{2}{*}{$x^{2}, 10.0$} & \multirow[t]{2}{*}{0.006} \\
\hline Negative & 20 & $57.1 \%$ & 14 & $40 \%$ & 23 & $79.3 \%$ & & \\
\hline Procalcitonin (ng/ml), median (range) & \multicolumn{2}{|c|}{$0.325(0.12-2.8)$} & \multicolumn{2}{|c|}{$1.92(0.10-2.96)$} & \multicolumn{2}{|c|}{$0.22(0.11-2.19)$} & KW, 7.422 & 0.024 \\
\hline
\end{tabular}




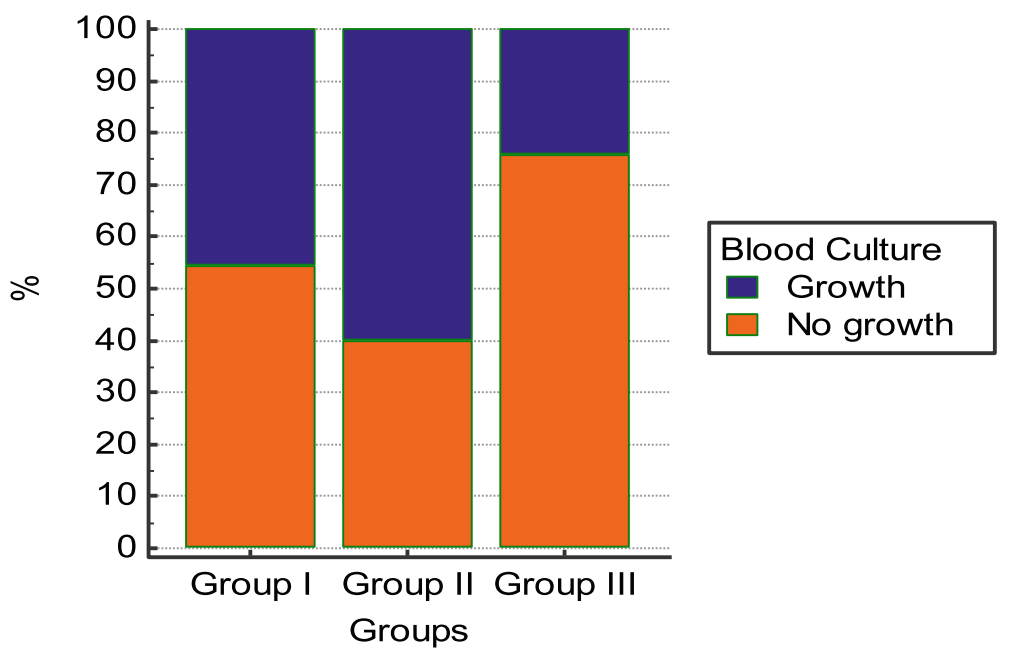

Fig. 1 Stacked bar chart showing blood culture among different studied groups

values $<0.5 \mathrm{ng} / \mathrm{mL}$ represent a low risk of severe sepsis and/or septic shock, and values $>2.0 \mathrm{ng} / \mathrm{mL}$ represent a high risk of severe sepsis and/or septic shock. Blood culture was done by using the BacT/ALERT Microbial Detection System. Then, subculture and antibiotic sensitivity by traditional methods. All other laboratory tests, including liver and renal function tests, and coagulation tests, underwent using the routine laboratory testing methods.

\section{Statistical analysis}

All statistical analysis was performed using the statistical software program, SPSS, for Windows version 25.0 (SPSS; Chicago, IL, USA). Categorical variables were presented in frequency and percentage, while numerical variables were presented with mean \pm standard deviation (SD). Comparative analysis and inferential statistics were performed using parametric independent $t$ test or Mann-Whitney $U$ test was used for comparison according to the Gaussian distribution of the variables. For categorical variables, the chi-square test (or Fisher's exact test if appropriate) was used. For all statistical tests, $p$ value $\leq 0.05$ was considered statistically significant. Multivariate logistic regression analyses were used to determine the predictor variables for the variceal bleeding.

\section{Results}

A 99 CLD patients participated in the present study, of whom 35 patients presented with the first attack of variceal bleeding, 35 patients presented with recurrent attacks of variceal bleeding, whereas 29 patients with no history of previous variceal bleeding served as the control group. The demographic and baseline characteristics of the subjects based on the groups are presented in Table 1 . The three groups were comparable in all demographics, baseline characteristics, and laboratory data. There was a statistically significant difference between studied groups regarding ascites, hemoglobin concentration, platelets, INR, albumin, and spleen diameter, $p<$ 0.05 .

Regarding blood culture and procalcitonin results, there was a statistically significant difference between the studied groups. Escherichia coli was the most common organism in blood culture-positive patients in the three groups, followed by Staphylococcus auerus, and the least prevalent organism was Klebsiella as were presented in Table 2. Patients with recurrent variceal bleeding had statistically $(p<0.05)$ the highest percentage of

Table 3 Procalcitonin in different blood culture results in the studied groups ( $n=99)$

\begin{tabular}{|c|c|c|c|c|c|c|}
\hline & \multicolumn{4}{|c|}{ Blood culture } & \multirow[t]{3}{*}{ Test } & \multirow[t]{3}{*}{$P$} \\
\hline & \multicolumn{2}{|c|}{ No growth $(n=55)$} & \multicolumn{2}{|c|}{ Growth $(n=44)$} & & \\
\hline & $N$ & $\%$ & $N$ & $\%$ & & \\
\hline \multicolumn{7}{|l|}{ Procalcitonin } \\
\hline Negative & 48 & $84.2 \%$ & 9 & $15.8 \%$ & $x^{2}, 44.22$ & $<0.0001$ \\
\hline Positive & 7 & $16.7 \%$ & 35 & $83.3 \%$ & & \\
\hline Procalcitonin (mg/dL), median (range) & \multicolumn{2}{|c|}{$0.22(0.1-2.45)$} & \multicolumn{2}{|c|}{$2.1(0.12-2.96)$} & MW, 5.99 & $<0.0001$ \\
\hline
\end{tabular}


Table 4 Univariate and multivariate logistic regression analysis to determine predictors of bleeding in studied population $(n=$ 99)

\begin{tabular}{lllll}
\hline Variables & Coefficients $\boldsymbol{\beta}$ & Std. error & OR & $\boldsymbol{P}$ \\
\hline Ascites & 0.535 & 0.196 & 1.70 & $\mathbf{0 . 0 0 6 6}$ \\
Albumin (g/dL) & -1.006 & 0.491 & 0.365 & $\mathbf{0 . 0 4 0}$ \\
Blood culture & 1.259 & 0.495 & 3.52 & $\mathbf{0 . 0 1 1 0}$ \\
Procalcitonin $(\mathbf{n g} / \mathbf{m l})$ & 0.772 & 0.271 & 2.16 & $\mathbf{0 . 0 0 4 5}$ \\
CTP & 0.864 & 0.291 & 2.372 & $\mathbf{0 . 0 0 3}$ \\
INR & 2.911 & 0.881 & 18.384 & $\mathbf{0 . 0 0 1}$ \\
Hemoglobin $(\mathbf{g} / \mathbf{d l})$ & -0.887 & 0.194 & 0.411 & $<\mathbf{0 . 0 0 0 1}$ \\
Platelet $\left(\times \mathbf{1 0} / \mathbf{m m} \mathbf{m}^{\mathbf{3}}\right)$ & -0.014 & 0.006 & 0.985 & $\mathbf{0 . 0 3 0}$ \\
Procalcitonin $(\mathbf{n g} / \mathbf{m l})$ & 0.96 & 0.35 & 2.61 & $\mathbf{0 . 0 0 6}$ \\
Hemoglobin $(\mathbf{g} / \mathbf{d l})$ & -0.91 & 0.21 & 0.40 & $<\mathbf{0 . 0 0 0 1}$ \\
Constant & 8.51 & & & \\
\hline
\end{tabular}

positive blood culture followed by patients with first variceal bleeding and the control $(60 \%$ vs $45.7 \%$ vs 24.1\%) respectively, as presented in Fig. 1.

In regarding procalcitonin results, patients with recurrent variceal bleeding had statistically the highest values of PCT followed by patients with first variceal bleeding and the control $(1.92$ vs 0.325 vs $0.22 \mathrm{ng} / \mathrm{ml})$ respectively.

Statistically, patients with positive blood culture had a higher value of PCT while patients with negative blood culture had a low value of PCT $(2.1 \mathrm{vs} 0.22 \mathrm{ng} / \mathrm{ml})$ respectively (Table 3 ).

In the univariate and multivariate logistic regression analysis model, high serum albumin was associated with reduced risk of bleeding (OR 0.365; 95\% CI, 0.491-1.006, $p=0.040$ ) while the other factors are associated with increased risk of bleeding. After adjusting the different parameters, procalcitonin, and hemoglobin only were the significant predictors for first or recurrent bleeding (OR 2.61; 95\% CI, 0.35$0.96, p=0.006$ ) (OR 0.40; 95\% CI, 0.21-0.91, $p<$ 0.0001 ), respectively (Table 4 ).

The odds ratio of the first attack of bleeding among bacteremic patients is 2.65 times more than nonbacteremic patients. However, the odds ratio of recurrent gastrointestinal bleeding among bacteremic patients is 4.71 times more than non-bacteremic patients. Also, the odds ratio of the first attack of bleeding among procalcitonin positive patients is 2.87 times more than procalcitonin negative patients. However, the odds ratio of recurrent gastrointestinal bleeding among procalcitonin positive is 5.75 times more than procalcitonin negative patients (Table 5 ).

CTP score at cutoff value of $>6$ is the most sensitive in predicting bleeding followed by hemoglobin at cutoff value of $\leq 9.6$. While hemoglobin at cutoff value of $\leq 9.6$ and procalcitonin $(\mathrm{ng} / \mathrm{dl})$ at cutoff value of $>1.76$ is the most specific in predicting bleeding $86.21 \%, 86.21 \%$ (CI 95\%) respectively (Table 6).

Our study illustrated that there was a significant difference between groups in Child-Pugh score, Child C presents in $40 \%$ of patients with the first attack of bleeding compared with $68.6 \%$ in patients with recurrent bleeding and $27.6 \%$ of those without bleeding as in Table 7.

\section{Discussion}

Bacterial infections are common in patients with cirrhosis, which include spontaneous bacterial peritonitis, urinary tract infections, pneumonia, bacteremia, and soft-tissue infections. The incidence of bacteremia is increased in cirrhotic patients, as they are not only immunocompromised but also exhibit excessive activation of pro-inflammatory

Table 5 Assessment of bacteremia and positive procalcitonin as a risk for gastrointestinal bleeding among studied population $(n=$

99)

\begin{tabular}{lll}
\hline Blood culture & \multicolumn{2}{l}{$\begin{array}{l}\text { Group (I) } \\
\text { Patient with first attack of bleeding }(\boldsymbol{n}=\mathbf{3 5})\end{array}$} \\
& No. & $\%$ \\
Positive & 16 & $45.7 \%$ \\
Negative & 19 & $54.3 \%$ \\
Odds ratio (OR) & $\mathbf{2 . 6 5}$ & \\
& & \\
Procalcitonin & Group (I) & \\
& Patient with first attack of bleeding $(\boldsymbol{n}=\mathbf{3 5})$ \\
& No. & \% \\
Positive & 15 & $57.9 \%$ \\
Negative & 20 & \\
Odds ratio (OR) & $\mathbf{2 . 8 7}$
\end{tabular}

Group (II) Group (III)

Patient with recurrent bleeding $(n=35) \quad$ Control patients $(n=29)$

No.

$21 \quad 60 \%$

$14 \quad 40 \%$

4.71

Group (II)

Patient with Recurrent bleeding $(n=35)$

No.

$\%$

21

$60 \%$

$14 \quad 40 \%$
No. $\quad \%$

$7 \quad 24.1 \%$

$22 \quad 75.9 \%$ 
Table 6 Specificity and sensitivity of different parameters in predicting esophageal bleeding (EVs) in our study $(n=99)$

\begin{tabular}{|c|c|c|c|c|c|c|c|}
\hline & Cutoff values & $\begin{array}{l}\text { Sens. \% } \\
(95 \% \mathrm{Cl})\end{array}$ & $\begin{array}{l}\text { Spec. \% } \\
(95 \% \mathrm{Cl})\end{array}$ & $\begin{array}{l}\text { Positive predictive } \\
\text { value }(95 \% \mathrm{Cl})\end{array}$ & $\begin{array}{l}\text { Negative predictive } \\
\text { value }(95 \% \mathrm{Cl})\end{array}$ & $\begin{array}{l}\text { AUC } \\
(95 \% \mathrm{Cl})\end{array}$ & $P$ \\
\hline Albumin (g/dL) & $\leq 2.86$ & $54.29 \%$ & $75.86 \%$ & $84.4 \%$ & $40.7 \%$ & 0.679 & 0.0128 \\
\hline Procalcitonin (ng/ml) & $>1.76$ & $47.14 \%$ & $86.21 \%$ & $88.9 \%$ & $40.3 \%$ & 0.668 & 0.0024 \\
\hline Child score & $>6$ & $85.71 \%$ & $41.38 \%$ & $77.9 \%$ & $54.5 \%$ & 0.680 & 0.0023 \\
\hline INR & $>1.38$ & $65.71 \%$ & $82.76 \%$ & $90.2 \%$ & $50 \%$ & 0.484 & $<0.0001$ \\
\hline Hemoglobin (g/dl) & $\leq 9.6$ & $84.29 \%$ & $86.21 \%$ & $93.7 \%$ & $69.4 \%$ & 0.895 & $<0.0001$ \\
\hline
\end{tabular}

cytokines and are thus prone to infections [5]. Procalcitonin (PCT) is used as a biomarker for the diagnosis of bacteremia, sepsis, and septic shock [14].

On univariate analysis, hemoglobin level was a good predictor for variceal bleeding and bacteremia. Also, albumin level was a good predictor for variceal bleeding and bacteremia. So increased hemoglobin and albumin are associated with reduced risk of bleeding but positive blood cultures, ascites, etc. are associated with increased risk of bleeding.

These results are parallel with Kothari and colleagues who showed that hemoglobin level is lower in the bleeding esophageal varices group $(8.26 \pm 2.25)$ than the nonbleeding group $(8.93 \pm 2.37)$ [15]. Grothaus and his colleagues also reported similar results that patients with bleeding events after EVL had significantly lower hemoglobin levels [16].

Regarding platelet counts, there was a statistically significant difference between the studied groups and it was a significant predictor for variceal bleeding. This is consistent with Kothari et al. who showed that platelet count is lower in the esophageal varices bleeding group than the non-bleeding group. Cut off $134 \times 103 / \mathrm{mm} 3$ was significant predictor of variceal bleeding (sensitivity $=80.33$, specificity $=62.41, \mathrm{OR}=6.77)[15]$. Giannini et al. and Schepis et al. who reported that a platelet count of less than 100,000 can be used as a predictor of variceal bleeding, and of less than 90,000 is associated with an increased risk of having variceal bleeding by nearly 2.5 -folds $[17,18]$.

Bacteremia increased the risk of the first attack of variceal bleeding by 2.65 times more than non-bacteremic patients and increased the risk of recurrent bleeding 4.71 times more than non-bacteremic patients. Our results showed E. coli was the most common organism in blood culture-positive patients in the bleeding and non-bleeding groups, followed by Staph. aureus, and the least prevalent organism was Klebsiella. This is consistent with Bunchorntavakul and Chavalithamrong who showed that the major causative organisms are gram-negative bacteria, e.g., E. coli, Klebsiella spp. and Enterobacter spp., whereas gram-positive bacteria, especially Enterococci and Staphylococcus aureus, comprise about $20 \%$ and anaerobes only 3\% [19]. In addition, Guarner et al. had reported that bacteremia presents more frequently in patients with variceal bleeding [20].

Our results demonstrated that median procalcitonin levels were significantly higher in both bleeding groups than the control group and its level was higher in patient with recurrent bleeding than the first attack of bleeding. Our results agree with Juutilainen et al., who showed that, with the cutoff value for PCT level set to $0.5 \mathrm{ng} / \mathrm{ml}$, diagnostic sensitivity to bacterial infection was $65 \%$, and specificity was $96 \%$. Additionally, at serum PCT levels higher than $1.2 \mathrm{ng} / \mathrm{ml}$, sensitivity reaches $100 \%$ [21].

In addition, these results are consistent with the findings of Neofytos and his colleagues [22]. Lee SH et al. reported that leukocytes, induced by inflammatory response, produce excessive amounts of pro-inflammatory cytokines, such as interleukins 1,6 , and 8 and tumor necrosis factor$\alpha$ which induce the production of PCT that expressed by nearly all kinds of parenchymal cells [23].

Table 7 Severity of liver disease in studied population $(n=99)$

\begin{tabular}{|c|c|c|c|c|c|c|c|}
\hline & \multicolumn{2}{|c|}{ Group (I) } & \multicolumn{2}{|l|}{ Group (II) } & \multicolumn{2}{|c|}{ Group (III) } & \multirow[t]{3}{*}{$P$} \\
\hline & \multicolumn{2}{|c|}{$\begin{array}{l}\text { Patient with first attack of bleeding } \\
(n=35)\end{array}$} & \multicolumn{2}{|c|}{$\begin{array}{l}\text { Patient with recurrent bleeding } \\
(n=35)\end{array}$} & \multicolumn{2}{|c|}{ Control patients $(n=29)$} & \\
\hline & No. & $\%$ & No. & $\%$ & No. & $\%$ & \\
\hline CTP score, median (range) & $9(5-12)$ & & $10(5-14)$ & & $8(5-13)$ & & 0.002 \\
\hline \multicolumn{8}{|l|}{ CTP class } \\
\hline$A$ & 8 & $22.9 \%$ & 2 & $5.7 \%$ & 12 & $41.4 \%$ & 0.003 \\
\hline B & 13 & $37.1 \%$ & 9 & $25.7 \%$ & 9 & $31.0 \%$ & \\
\hline C & 14 & $40 \%$ & 24 & $68.6 \%$ & 8 & $27.6 \%$ & \\
\hline
\end{tabular}




\section{Conclusion}

Our study revealed that bacteremia and high procalcitonin level are risk factor variceal upper GI bleeding in cirrhotic patients. Procalcitonin can be used as an easily measurable and surrogate biomarker for bacteremia and variceal bleeding in cirrhotic patients even absence of leukocytosis. Further studies with large sample size are needed for more illustration of our study's results.

\section{Abbreviations}

ALT: Alanine aminotransferase; AST: Aspartate transferase; BMI: Body mass index; BUN: Blood urea nitrogen; CLD: Chronic liver disease; FBG: Fasting blood glucose; INR: International normalized ratio; HbA1C: Hemoglobin A1C; UGIB: Upper gastrointestinal bleeding; PCT: Procalcitonin

\section{Acknowledgements}

The authors would like to thank all patients for their participation in this research.

\section{Authors' contributions}

SZ generated the research idea, MZ and WM performed the clinical examination, HS performed the laboratory analysis, and AG wrote the largest part of the manuscript. All authors shared in analyzing and interpreting the patient data and in writing the manuscript. All authors read and approved the final manuscript.

\section{Funding}

This research did not receive any specific grant from funding agencies in the public, commercial, or not-for-profit sectors.

\section{Availability of data and materials}

The datasets used and/or analyzed during the current study are available from the corresponding author on reasonable request.

\section{Ethics approval and consent to participate}

The Zagazig University institutional review board approved the study (ZUIRB\#5470-7-7-2019). Written informed consent was obtained from all individual participants in the study.

\section{Consent for publication}

Not applicable.

\section{Competing interests}

The authors declare that they have no competing interests.

\section{Author details}

${ }^{1}$ Internal Medicine Department, Faculty of Medicine, Zagazig University, Zagazig, Sharkia 44519, Egypt. ${ }^{2}$ Clinical Pathology Department, Faculty of Medicine, Zagazig University, Zagazig, Egypt.

Received: 10 October 2020 Accepted: 7 January 2021

Published online: 25 January 2021

\section{References}

1. Zhou WC, Zhang QB, Qiao L (2004) Pathogenesis of liver cirrhosis. World J Gastroenterol 20:7312-7324

2. Berzigotti A, Gilabert R, Abraldes JG et al (2013) Non-invasive prediction of clinically significant portal hypertension and oesophageal varices in patients with compensated cirrhosis. Am J Gastroenterol 103(5):1159-1167

3. Laine L, Laursen SB, Zakko L et al (2018) Severity and outcomes of upper gastrointestinal bleeding with bloody vs coffee-grounds hematemesis. Am J Gastroenterol 113(3):358-366

4. Garcia-Tsao G, Bosch J (2010) Management of varices and variceal hemorrhage in cirrhosis. N Engl J Med 362(9):823-832

5. Moon AM, Dominitz JA, loannou GN et al (2016) Use of antibiotics among patients with cirrhosis and upper gastrointestinal bleeding is associated with reduced mortality. Clin Gastroenterol Hepatol 14(11):1629-1637

6. Ochei J, Kolhatkar A (2000) Pus abscess and wound drain. Medica Laboratory Science: Theory And Practice. Tata McGraw-Hill Education 70:622
7. Simon L, Gauvin F, Amre DK et al (2004) Serum procalcitonin and C-reactive protein levels as markers of bacterial infection: a systematic review and meta-analysis. Clin Infect Dis 39(2):206-217

8. Meisner M, Brunkhorst FM, Reith HB et al (2000) Clinical experiences with a new semi-quantitative solid phase immunoassay for rapid measurement of procalcitonin. Clin Chem Lab Med 38(10):989-995

9. Bartoletti M, Giannella M, Lewis RE et al (2016) Bloodstream infections in patients with liver cirrhosis. Virulence 7(3):309-319

10. Tafarel JR, Tolentino LH, Correa LM et al (2011) Prediction of esophageal varices in hepatic cirrhosis by noninvasive markers. Eur J GastroenterolHepatol 23(9):754-758

11. Thalheimer U, Triantos CK, Samonakis DN et al (2005) Infection, coagulation, and variceal bleeding in cirrhosis. Gut. 54(4):556-563

12. Yang MT, Chen HS, Lee HC et al (2007) Risk factors and survival of early bleeding after esophageal variceal ligation. Hepato-Gastroenterology 54(78): 1705-1709

13. Muhammad SK, Shaikh MA, Shaikh BA (2012) Sensitivity, specificity and predictive values of noninvasive markers of oesophageal varices in cirrhosis of liver. Asian J Med Res 1:98-102

14. Casado-Flores J, Blanco-Quirós A (2001) Procalcitonin: a new marker for bacterial infection. An Esp Pediatr 54(1):69-73

15. Kothari HG, Gupta SJ, Gaikwad NR et al (2019) Role of non-invasive markers in prediction of esophageal varices and variceal bleeding in patients of alcoholic liver cirrhosis from central India. Turk J Gastroenterol 30(12):10361043

16. Grothaus J, Petrasch F, Zeynalova S et al (2010) Risk factors for bleeding complications after endoscopic variceal ligation therapy. Z Gastroentero 48(10):1200-1206

17. Schepis F, Camma C, Niceforo D (2001) Which patients with cirrhosis should undergo endoscopic screening for esophageal varices detection? Hepatology. 33(2):333-338

18. Giannini E, Botta F, Borro P et al (2003) Platelet count/spleen diameter ratio: proposal and validation of a non-invasive parameter to predict the presence of oesophageal varices in patients with liver cirrhosis. Gut. 52(8): 1200-1205

19. Bunchorntavakul C, Chavalithamrong D (2012) Bacterial infections other than spontaneous bacterial peritonitis in cirrhosis. World J Hepatol 4(5): 158168

20. Guarner C, Soriano G (2005) Bacterial translocation and its consequences in patients with cirrhosis. Eur J Gastroenterol Hepatol 27(1):27-31

21. Vänskä M, Koivula I, Hämäläinen S et al (2011) High pentraxin 3 level predicts septic shock and bacteremia at the onset of febrile neutropenia after intensive chemotherapy of hematologic patients. Haematologica. 96(9):1385-1389

22. Neofytos D, Treadway S, Ostrander D et al (2013) Epidemiology, outcomes, and mortality predictors of invasive mold infections among transplant recipients: a 10-year, single-center experience. Transpl Infect Dis 15(3):233242

23. Lee SH, Chan RC, Wu JY et al (2013) Diagnostic value of procalcitonin for bacterial infection in elderly patients: a systemic review and meta-analysis. Int J ClinPract 67(12):1350-1357

\section{Publisher's Note}

Springer Nature remains neutral with regard to jurisdictional claims in published maps and institutional affiliations. 